\title{
Perceived Learning Strategies Employed by Preschoolers in Learning English
}

\author{
Zuraina Ali \\ Centre for Modern Languages, Universiti Malaysia Pahang, 26600 Pekan, Pahang \\ zuraina@ump.edu.my
}

\begin{abstract}
Learning strategies are plans that learners use to achieve their learning goals. The current study investigates the perceived uses of learning strategies among preschoolers, namely Basic rehearsal strategies, Complex rehearsal strategies, Basic elaboration strategies, Complex elaboration strategies, Basic organizational strategies, Complex organizational strategies, Comprehension monitoring strategies and Affective and motivational strategies among preschoolers in learning English. The study employed 23 preschool teachers as the samples having semi-structured interviews as the research instrument. The data collection period took four (4) months. Content analysis was employed to analyze the data in the current study. The obtained data was validated by the members of the faculty. Findings from the study showed that the learning strategies were implemented by the preschoolers in the course of their learning. Yet, the degree of the usages of the learning strategies varies from one to another. The study implied that deciding on learning games, teaching aids, and asking appropriate questions during lessons are essential to maximize the learning strategies among children in their early learning.
\end{abstract}

Keywords:

preschoolers; learning strategies; English

This is an open access article under the $\mathrm{CC}-\mathrm{BY}-\mathrm{NC}$ license.

\section{INTRODUCTION}

Learning strategy is vital for the success of learning. It assists learners in knowing the appropriate strategies that may be used in their learning. On a different note, the literature showed that children learn. At the same time, they play (healthychildren.org, 2019), and in a study, it was demonstrated that primary school children employed various learning strategies, for instance, retrieving words learned from drawing and using thematic contexts as well as code-switching (Coyle $\&$ Valcarcel, 2002). Another study on the use of learning strategies concerned with elaboration strategy employed by teachers in that they created internal and external links with the information received (Bayram, 2013).

It can be stated, therefore, that previous studies of learning strategies have not dealt with investigating their usages in a more focused nature or, in other words, in what aspect is the learning strategies are examined. In the current study, preschool teachers were employed to obtain perceived learning strategies developed by Weinstein and Mayer (1983) among preschool students. In particular, the objectives of the study are to identify the eight (8) learning strategies namely Basic rehearsal strategies, Complex rehearsal strategies, Basic elaboration strategies, Complex elaboration strategies, Basic 
organizational strategies, Complex organizational strategies, Comprehension monitoring strategies and Affective and motivational strategies in learning English as a second language among preschoolers.

\section{THEORETICAL PERSPECTIVES}

\section{Definition of learning strategy.}

Learning strategy concerns with behaviors and thoughts demonstrate by a learner when they are engaged in learning and assist him/her in his/ her encoding process (Weinstein \& Mayer, 1983). Further, they redefine the term in that learning strategy relates to the behavior of a learner that gives impact to the way the learner processes information. They categorized learning strategies into eight (8) categories.

(1) The Basic rehearsal strategies concerns with repeating the names of items. For example, asking students to remember the order of the planet. In (2) Complex rehearsal strategies, tasks include copying, underlining, or shadowing the material presented in class. An example of a task in this category is asking students to underline the main events in a story, or they can be asked to copy portions of a lesson about a particular topic. (3) Basic elaboration strategies deal with forming a mental image or sentence-relating an item in each pair for a paired-associate list of words. Teachers can ask students to form a phrase or sentence relating the name of states or creating a mental image of the scene described in a poem. (4) Complex elaboration strategies relate to paraphrasing, summarizing, or explaining new information with that of existing knowledge. The example of the task includes creating an analogy between the operations of the computer versus the post office. (5) Basic Organizational Strategy relates to requiring students to group or order items they need to learn from a list or a section of prose. Students may be asked to organize vocabulary they learn into parts of speech. They may also be asked to create a chronology of events in the history class. (6) Complex Organizational Strategy concerns with outlining a passage or creating a hierarchy. Teachers may ask students to draw to show relationships. (7) Comprehension monitoring strategies deal with asking oneself on his/her understanding of the things learned. Selfquestioning is one of the examples used in this strategy. (8) Affective and motivational strategies are the strategies that are used that help students being alert and relaxed to help overcome test anxiety. A common task is to avoid external distractions by studying in a quiet place or using thought stop to prevent the idea of doing poorly in the exam.

On a different note, since the research deals with the use of language among the preschools, a definition of learning strategies concerning language needs to be highlighted as well. Montaño (2017) defines learning strategies as tactics that a learner uses to gain control in the process of learning a language. In this learning, the role of the teachers is to facilitate learning among their learners and make this process visible. For 
learning to be successful, teachers, therefore, need to examine the needs and biographies of the learners.

\section{Jean Piaget's Theory of Cognitive Development}

The theory developed by Jean Piaget suggests that children learn when they interact with the environment. Piaget argues that children construct meaning or the things that happen around them when there is an understanding of the discrepancies between what they already know with what they discover in their environment (McLeod, 2018). In particular, the theory proposes three (3) main components of the cognitive development of the children.

1. Schemas - it is a building block of knowledge. It concerns how children organize their knowledge in that they relate one aspect of the world that includes the meaning that receives from the objects around them, actions that other people are demonstrating, and the abstract knowledge they gain.

2. Adaptation process - it involves assimilation, accommodation, and equilibrium. Assimilation involves using the existing schema to deal with a new object/ situation. Accommodation occurs when children need to change the way they deal with a new object/situation due to their existing schema does not work at that particular time. Equilibration is the force that makes children move development throughout learning.

3. Stages of cognitive development. The stages involve sensorimotor, preoperational, concrete operational, and formal operational. These stages involve children's learning from birth (sensorimotor), toddlerhood (preoperational). Also, learning occurs among children between the ages of 7 to 11 years (concrete operational) until their adulthood.

\section{RESEARCH METHOD}

The study uses qualitative data inquiry in collecting its data for the current study. It is due to obtaining an in-depth of the preschool teachers' way of imposing the learning styles among their preschoolers. Moreover, the method is used as it enables the researcher to understand and analyze the interaction between her and the preschool teachers involved in the current study. Hatch (2002) states that such can be done when a researcher uses an audio recorder (or video recorder) and later understand as well as analyze beyond the specific words of the recorded conversation.

\section{Research instrument}

An interview protocol was used to gauge the preschool teachers' method of imposing the learning strategies among the preschoolers. It consists of four (4) open-ended semi-structured 
interview items, namely the approach of teaching in general, the activities employed in the four language skills, the kind of tools used to assist learning, and the module used by the preschoolers. The instrument was validated by the researcher's colleague. Comments were made accordingly after the revision of the instrument was written to the researcher. After the data was collected, reliability checking, i.e., a peer-review, was conducted by another colleague. It was carried out to seek any comment on the findings that emerged from the data for credibility and trustworthiness of the data collected (Merriam \& Tisdell, 2016).

\section{Research Sample}

The samples in the current study were 23 preschool teachers teaching in preschools in three (3) districts of Pahang (East Coast of Malaysia), namely Cameron Highlands, Pekan, and Kuantan. Besides, data saturation is essential to be addressed when conducting an interview. In the current study, since there was no new data emerge having to interview 23 preschool teachers, it could be stated that the collected data has reached a saturation point. Burmeister (2012) argues that the depth of the data rather than the number of respondents per se is more important in justifying the attainment of data saturation. Concerning their ages, they are from 21 to 50 years old and have been working in the Early Childhood Education (ECE) industry from two (2) to 20 years. In terms of their academic qualifications, they obtained a diploma, degree, or master in that their majors were in ECE, Accounting, Operation Management, Social Sciences, Music, English, Building Surveying, Information Technology, Business Administration, and Biomedical. The levels of education of the preschool teachers various, yet they have one common characteristic in that they are interested in teaching children. Since they are degree holders, it can be argued that they can teach the preschoolers of basic reading and calculating. Furthermore, they went to the training and short courses about ECE that were conducted by the Education Ministry of Malaysia for preschoolers and their respective franchisers.

\section{Data collection and analysis procedures}

Simultaneous processes are practiced when collecting and analyzing data in qualitative data inquiry. It is misleading to collect the data and later analyze them as the qualitative design is emergent (Merriam \& Tisdell, 2016). In the current study, the researcher did not know ahead further questions she would be asking or where the next preschool would be unless data were analyzed while they were being collected. In the action research, as in the present study, Merriam and Tisdell (2016) state the interview protocol was prepared as an official guide for the researcher to ask questions during interviews only. In doing the content analysis, he hunches direct a researcher in refining and confirming them (Merriam \& Tisdell, 2016). Thus, every time the data was collected, the data analysis was ongoing as the researcher planned, 
acted, observed, and reflected the data that was being collected. Also, coding of the data and presenting initial themes started from the beginning in that it required the researcher to arrange codes and formulate themes at various stages to show how the process of analysis has extended.

\section{LITERATURE REVIEW}

\section{Learning through playing}

The concept of 'learning through playing' is synonymous with children. Yet, often it is overlooked by the cognitive views of how children play while learning (Alcock, 2016). In asking them to memorize days of the week, for instance, learning does not merely give them a piece of the list to be memorized. Instead, they need room for learning while playing. The healthychildren.org (2019) outlines that children at the age of four (4) to six (6) years old learn when they :

a) can sing and dance

b) listen to stories

c) are given time and space to act out

d) are allowed to move between makebelieve and reality

e) can interact with peers

f) have the chance to try a variety of movements (hopping, climbing, etc.)

g) have limited access to screen time, and

h) are provided playful learning approaches versus structured learning approaches (reading and memorization)

\section{Learning strategies employed by children}

Learning strategies demonstrate by children can be observed by the way they elaborate, organize, memorize, and answer the questions that are asked by the teachers. In learning English as a Foreign Language (FL) among children, Coyle and Valcarcel (2002) found that they learned the language using these learning strategies:

a) anticipating to answer the teacher's questions

b) recalling vocabulary from drawing and pictures

c) recalling vocabulary with the thematic context

d) code-switching to overcome the limitation in FL knowledge

e) using prior knowledge when they are engaged with games/ stories

Using a mixed-method research design, Gunning and Oxford (2014) investigated the effects of strategy instruction on oral instructions among six (6) graders. The study showed that the success of learning strategies among the children could only be enhanced when they were aware of them. The children could be mindful of the strategies and use them when the teachers enhance the strategies in their instructions.

\section{FINDINGS AND DISCUSSION}

\section{Main theme: Basic rehearsal strategies}

In the strategies, learners seem to parrot the input given by the teachers. They rehearse by 
repeating the things they learned according to the use of appropriate materials.

\section{Sub-theme 1: Playing flashcards for the lesson learned.}

Teacher 5 states, "Students were asked to play flashcard and poison box first before they were asked to rehearse on the things they learned. Then, we give a little bit of revision before asking them to do exercises in the book". Teacher 2 did the same procedures in that flashcard were used to rehearse students' understanding of the contents they learned. She said, "We use flashcards depending on the suitability of the lessons. Later, we use Read Easy, and that book is used to rehearse the learning they had before doing exercises in the book".

\section{Sub-theme 2: 15-minutes rehearsal}

Rehearsal also is conducted if a class session ends 15 minutes early. Teacher 2 further said, "If the lesson ends much earlier, let say 15 minutes. So we used that time to rehearse the words, phrase, or lessons they learned".

Rehearsing is important to enhance the preschoolers' memories. In the current study, flashcards and poison boxes were used before letting students write in their books. Also, rehearsal may always take place if teachers had additional time to recall the lessons the preschoolers learned on a particular day. The results of the study corroborate with that of a study that found that rehearsal training improved recall among children aged five (5) to nine (9) when they were assigned to be in either cumulative rehearsal group or interactive imagery group (Miller, McCulloch, \& Jarrold, 2015). The former method in their study was used to retain information in short-term memory. In the current study, the teachers required the preschoolers to rehearse by playing flashcards and poison boxes. Hence, when they do the exercises in the workbook, they repeated the lesson learned while they were playing the games in the previous session.

\section{Main theme: Complex rehearsal strategy}

Since the students are still at the early stage of schooling, there are not many writing activities as in asking students to copy or underline materials they have learned. The only activity is asking students to copy the letters they learned in a conventional writing exercise book.

\section{Sub-theme 1: Use of conventional writing book}

Teacher 3 used an ordinary writing book in asking students to copy letters they learned. She said, "We use the conventional writing book ... that double line writing book and ask students to copy the letters they learned".

\section{Sub-theme 2: Reciting do' a to shadow lesson learned. \\ The Complex Rehearsal Strategies also involve asking the preschoolers to recite prayers (do' a) in English to shadow the need for reciting it before they begin eating. Teacher 21 described}


the strategy that her preschoolers practiced in this excerpt:

Researcher : So, all the prayers are recited in English?

Teacher $6 \quad$ Yes and the do' a that they recite the fastest is the one to begin eating. The preschoolers manage to recite the do' a before going to sleep. But they are still not able to recite the do' a before entering toilet

In learning English, Complex Rehearsal Strategy concerns with adding personal meanings to a lesson learned (Tay, Unal, \& Kafadar, 2016 ). In the current study, preschoolers were required to recite the do 'a and utter its translation in English so that they realize its meaning. The Complex Rehearsal Strategy, therefore, took place when the preschoolers not only were required to memorize the do' a, alongside it was necessary for them to understand its meaning in English (and not their mother-tongue, i.e., Malay).

\section{Main theme: Basic elaboration strategies}

In these strategies, the uses of thematic learning enable the students to form a mental image of the concept they are learning.

\section{Sub-theme 1: Use of weekly themes}

An example of weekly themes is demonstrated by Teacher 22, "We based the learning of English according to themes. For example, according to food and vehicles.

\section{Sub-theme 2: Use of themes with songs}

Teacher 18 gave her opinion on the use of themes to gauge students' Basic Elaboration Strategy to visualize the learning on that day. "When we have reading activities, let say the theme is part of a body. We will let the students listen to songs: Head and shoulder, knee, and toe. Then we teach them spelling". Teacher 2 also combined thematic learning with songs. She asserted, "We use the kindergarten's module. For instance, if we want to teach about a particular theme, we have the songs already".

\section{Sub-theme 3: Use of themes with arts and crafts}

Meanwhile, Teacher 11 used thematic learning to introduce occupation to the students. For 4-year-old students, she asked them to do arts and crafts according to what they have learned. She explained, "After we taught the preschoolers about the theme occupation, we then have craft activities with 4-year-old students".

\section{Sub-theme 4: Use of themes with posters}

For Teacher 6, the students' ability to understand a material using thematic learning makes them paste wall posters for a quick demonstration of the Basic Elaboration Strategy. She said, "We arrange the wall poster according to themes. We let parents know the theme we are learning this week and ask parents to contribute pictures or photos. Then we paste them on the wall. Teacher 5 added in that she clarified, "If we learn about the classroom, we paste vocabularies 
that are related to the theme. We paste on the wall for five (5) days only. So, in learning English, we have two (2) weeks to learn one (1) theme. We put down all the pictures/photos when the children have learned about the theme".

In Elaboration Strategy, preschoolers use and expand what they learned. In the current study, the uses of themes enabled them to learn the target vocabulary and associating it with pictures. The preschoolers then discussed the theme with their teachers in the class. Besides, they expand the target words by listening to songs, doing arts and crafts, and pasting posters on the walls. That being said, showed that the findings of the current study corroborated with the study by Willoughby, Porter, Belsito, and Yearsley (1999) in that creating a mental picture was a powerful strategy in learning among young learners. The strategy works even though they have limited background knowledge of what they are currently learning. (Meniado, 2016)

\section{Main theme: Complex elaboration strategies}

In this strategy, students need to demonstrate the ability to paraphrase, summarize, or describe new information with that of existing knowledge.

\section{Sub-theme 1: Relating new vocabulary with mother-tongue}

The preschoolers showed this strategy by understanding the new vocabulary and related it to the first language they used. Such was the kind of task that was suitable for the group of age as they did not learn writing essays in the preschools. Teacher 26 described this strategy, "The preschoolers watch $D D \&$ Friends. If they know the song in Malay, we will then teach the English version of the song. Like the song head and shoulders, knee, and toe. So in that song, DD uses the word 'faster' to call her friends. So they learn that 'faster' is 'cepat.'

\section{Sub-theme 1: Use of translation}

Teacher 16 added that translation enabled her preschoolers to understand simple English. She repeatedly used the word to allow them to pick up and use it in the preschoolers' conversation. She said, "We communicate in English. So, when the preschoolers did not understand, we translate it (the vocabulary they did not understand) in English. For example, when we say the word 'Silent, please.' They do not understand what the word is. So we let them know. For preschoolers, we just need to communicate using simple English. Another example we teach students simple English is asking permission to go to the toilet. They always say, "Teacher, I want to toilet."

Findings from the current study showed that the preschoolers demonstrated a comparison type of Complex Elaboration Strategy. They compare the vocabulary they were learning with their existing knowledge of the vocabulary. Bayram (2013) argues that the techniques allow learners to create internal and external links among various information that they obtain. They construct and reconstruct knowledge by inferencing the 
knowledge they are learning with their previous ones. The learning demonstrated by the children in this regard is in line with Piaget's theory whereby children used existing knowledge to deal with the content they were learning. This assimilation process requires the children to make new knowledge fits in with their understanding of the world (Cherry, 2020)

\section{Main theme: Basic Organizational Strategy}

The strategy teaches preschoolers to a group or arranges items they need to learn from a list or section.

\section{Sub-theme 1: Use of list to teach new vocabulary}

In implementing this strategy, teachers used a set of lists to teach preschoolers new vocabulary they needed to learn. Teacher 20 asserted that the list was used in the language classes, i.e. Arabic, Malay, and English. She explained, "For Arabic, Malay and English, we list out 100 words the preschoolers need to learn. The teacher has to teach these words to them in a year. The target vocabularies are according to the theme in that particular week".

The Basic Organization Strategy demonstrated in the current study enabled the preschoolers to organize the vocabulary they learn by listing them according to themes they learn on a particular week. They compared similarities and dissimilarities of vocabularies that can be categorized into a theme (Neer, 2016). Smith and Weinstein (n.d.) state the use of list enabled learners to make connections between the theme and vocabulary they are learning. Such was shown by the preschoolers in the current study in that they were able to think of the vocabularies that could be categorized under the same theme.

\section{Main theme: Complex Organizational Strategy}

The strategy concerns with outlining a passage or creating a hierarchy. Teachers may ask students to show a relationship among items they are learning.

\section{Sub-theme 1: Grouping words to learn compound words}

Teacher 6 taught compound words using the Complex Organizational Strategy. She required her preschoolers to show the relationship of two (2) words that can be made to structure compound words. She elaborated, "Among the examples of language games is compound words. We will introduce the word family first to the preschoolers. For example, wheel and chair ... so they become wheelchair. Finger and nail so they become fingernails. Jelly with fish, so they become jellyfish. To do this, we use word and picture cards. So, the preschoolers will arrange the cards to structure a compound noun".

In the current study, the grouping is the strategy that was used to structure compound words. The effectiveness of the strategy can be compared to the study conducted by Elsayed (2015). The use of grouping in his study enabled the primary students to link information to each 
other. His findings demonstrated that in learning mathematics, participants were able to organize mathematics content in their minds. As a result, they developed their critical thinking and improved their academic achievement. Nevertheless, he proposed that a proper lesson plan needed to be prepared for the success of the strategy.

\section{Main theme: Comprehension monitoring strategies}

They are the strategies that a learner use to check his/her understanding of the things he/she has learned. It deals with asking oneself of his/her understanding of the things he learned. Selfquestioning is one of the examples used in these strategies.

Furthermore, they are metacognitive strategies that require learners to establish learning goals and access the degree to which they are being met - and, if possible, improve the strategies if they are not able to meet the goals (Weinstein \& Mayer, 1983).

\section{Sub-theme: Ask-aloud to test comprehension}

Teacher 20 explained that she asked-aloud whether the preschoolers understand or otherwise the lesson that they were learning. She said: They don't have a problem when I ask them to show which is yellow in the exam. But when I ask them to spell, they can't. So, when

they get the correct answer they are probably just guessing".

In the current study, the preschoolers were able to identify yellow as a color. Yet, their comprehension of the concept of yellow was not able to take them to the next level when the teacher asked them to spell the word 'yellow.' These results reflected the study conducted by Meniado (2016) concerning the learners' setting of learning English as a second language and their orientations to the language. Since the majority of the preschoolers in the current study did not use English as their first language at home, at a time, they were unsure of their meaning in English but comprehend what the word is. It is recommended, therefore, that teachers need to be ready to use comprehension strategy in their teaching more effectively (Meniado, 2016).

\section{Main theme: Affective and motivational strategies.}

The uses of affective and motivational strategies enable preschoolers to be relaxed and to overcome their learning. Also, the uses of the strategies help them to lower their anxiety level. In the current study, the uses of the strategies were not directly concerned with exams. Instead, they were used to make the preschoolers became comfortable in learning the lesson that was taught by the teachers.

\section{Sub-theme 1: Use of affective strategy to avoid confusion \\ Teacher 12 employed the strategies to} prevent her preschoolers' confusion in learning pronunciation in English versus Malay. She described, "As long as they did not finish reading all the eight (8) books in Malay, we'll not going to 
introduce them to English phonics. The reason being they'll be confused because the letter ' $c$ ' is pronounced [c] in Malay, but the pronunciation of the letter in English is [kei].

\section{Sub-theme 2: Use of persuasive techniques}

For two (2) preschool teachers teaching in the same school, persuasive techniques were used to overcome the situation when preschoolers were not comfortable answering a question in class although he/she knew the answer. This was due to he/she learned a different technique in his/her previous preschool. He/she was afraid that he/she gave a wrong answer when, in reality, it was just a matter of different techniques. To resolve this, the teachers let the preschooler take his/her time and introduced the new technique use in the existing preschool. The excerpt below narrates their experiences.

Teacher 5 : There is this five-year-old preschooler that came from Preschool A. He/she learned the different (reading) technique in the previous school. So, when we ask him/her to read, he/she just keeps quiet.

Teacher 6 Sometimes he/she knows, but he/she just does not want to express him/herself. He/she is afraid to read because he/she thinks when he/ she reads using different techniques, it'll be wrong.

Teacher 5 : For this type of student, usually, it'll take time for the preschooler to adapt to the new technique. Perhaps in a month up and to three (3) months, we persuade him/her to use the new technique (that is used in the preschool), slowly then he/she can use it.

The results of the Affective and Motivational Strategies employed by the preschoolers in the current study could be associated with their behaviors in learning. Such finding supports the work of Wijirahayu and Dorand (2018). Their study found that unless a good attitude was observed among learners, only then that the affective strategy could be achieved. In the current study, the preschoolers were not able to show selfencouragement in learning as they were still young and, therefore, with the assistance of the teachers, they showed a good learning attitude when they tolerated the new reading techniques taught by their teachers. The encouragement in learning demonstrated by the teachers and was obliged by the preschoolers as in asking the latter to complete one task at a time was another good attitude shown by the preschoolers. Such learning mirrors Piaget's adaptation process, particularly the accommodation process. Children need to be able to change the way they deal with objects/ actions/situations around them. However, to ensure learning can take place, accommodation, and assimilation processes need to work together to make the cognitive-developmental possible among the children (Bormanaki \& Khoshhal, 2017). 


\section{CONCLUSION}

The present research aimed to examine perceived learning strategies demonstrated by preschoolers in learning English. Since the interviews were not conducted among the preschoolers, it was, therefore, argued that the data in the current study were the kind of learning strategies shown by the preschoolers in learning English as a second language through the observation made by the teachers. This study has identified the learning strategies that were used by Weinstein and Mayer (1983) among the preschoolers when they are learning $L 2$. Yet, the degree of each learning strategy varies from one another. Nevertheless, the roles of teachers are paramount in ensuring the success of the learning strategies. The current study implied that playing the appropriate games, using the right teaching aids and asking proper questions to engage students in learning, enables the preschoolers to enhance their self-learning. The study contributes to our understanding of assisting preschoolers in using various learning strategies to maximize learning. Yet, being limited to interviewing the teachers, this study lacks listening to the preschooler's voice of how to they use the learning strategies throughout the learning of English. This would be a valuable area for further work. Last but not least, it is recommended to examine a particular learning strategy, and further investigate on it rather than all the learning strategies to be discussed at once.

\section{ACKNOWLEDGMENT}

This research work is supported by the Fundamental Research Grant Scheme FRGS/1/2018/SSI09/UMP/02/4 (RDU190188)

\section{REFERENCES}

Alcock, S. J. (2016). Young children playing: Relational approaches to emotional learning in early childhood settings (Vol. 12): Springer.

Bayram, T. (2013). Elaboration and Organization Strategies Used by Prospective Class Teachers while Studying Social Studies Education Textbooks Eurasian Journal of Education Research, 51, 229-252.

Bormanaki, H. B., \& Khoshhal, Y. (2017). The role of equilibration in Piaget's theory of cognitive development and its implication for receptive skills: A theoretical study. Journal of Language Teaching and Research, 8(5), 996-1005.

Burmeister, E., \& Aitken, L. M. . (2012). Sample size: How many are enough? Australian Critical Care, 25, 271-274. doi:10.1016/j.aucc.2012.07.002

Cherry, K. (2020). The Importance of Assimilation in Adaptation. Retrieved from https://www.verywellmind.com/what-isassimilation-2794821

Coyle, Y., \& Valcarcel, M. (2002). Chidlren's Learning Strategies in the Primary FL Classroom. CAUCE, 25, 423-458.

Elsayed, A. M. (2015). Effectiveness of Using Elaboration Theory in Teaching Mathematics to Develop Academic Achievement and Critical Thinking For Primary Students in Oman. International Journal of Humanities and Cultural Studies, 2(3), 851-865.

Gunning, P., \& Oxford, R. L. (2014). Children's learning strategy use and the effects of strategy instruction on success in learning ESL in Canada. System, 43, 82-100. doi:https://doi.org/10.1016/j.system.2013.12 .012

healthychildren.org. (2019). The Power of Play How Fun and Games Help Children Thrive. Retrieved from https://www.healthychildren.org/English/ages- 
stages/toddler/fitness/Pages/Caution-

Children-at-Play.aspx

Meniado, J. C. (2016). Metacognitive Reading Strategies, Motivation, and Reading Comprehension Performance of Saudi EFL Students. English Language Teaching, 9(3), 117-129.

Merriam, S. B., \& Tisdell, E. J. (2016). Qualitative Research: A Guide to Design and Implementation (Fourth Edition ed.): Johd Wiley $\&$ Sons

Miller, S., McCulloch, S., \& Jarrold, C. (2015). The development of memory maintenance strategies: training cumulative rehearsal and interactive imagery in children aged between 5 and 9. Frontiers in psychology, 6, 524-524. doi:10.3389/fpsyg.2015.00524

Montaño, J. (2017). Learning Strategies in Second Language Acquisition. US-China Foreign Language, $\quad 15 . \quad$ doi:10.17265/15398080/2017.08.001

Neer, M. ( 2016). How To Learn Better: Part 3 Elaboration. Retrieved from https://dataworksed.com/blog/2016/01/how-to-learn-betterpart-3-elaboration/
Smith, M., \& Weinstein, Y. (n.d.). Learn How to Study Using Elaboration for Students, for Researchers, for Teachers, Learning Scientists Posts. Retrieved from https://www.learningscientists.org/blog/2016/ 7/7-1

Tay, B., Unal, M., \& Kafadar, T. (2016 ). The Use of Rehearsal Strategies in Social Studies Education Textbooks by Prospective Classroom Teachers

International J. Soc. Sci. \& Education, 6(3), 280290.

Weinstein, C. E., \& Mayer, R. E. (1983). The teaching of learning strategies. Innovation abstracts, 32, 315-327.

Wijirahayu, S., \& Dorand, P. (2018). Affective strategies, attitudes, and a model of speaking performance development for engineering students. Journal of Physics: Conference Series, 948, 012024. doi:10.1088/17426596/948/1/012024

Willoughby, T., Porter, L., Belsito, L., \& Yearsley, T. (1999). Use of Elaboration Strategies by Students in Grades Two, Four, and Six. The Elementary School Journal, 99(3), 221-231. 